\title{
Proteinuria in Children Living with HIV on Highly Active Antiretroviral Therapy (Haart)
}

\author{
Lucie Charlotte Ollandzobo Ikobo ${ }^{1,2 *}$, Roland Bienvenu Ossibi Ibara ${ }^{1,3}$, Neli Yvette Ngakengni ${ }^{1,4}$, \\ Laren Babomi ${ }^{1}$, Gaston Ekouya Bowassa ${ }^{1,4}$, Linda Tchidjo Ngamo ${ }^{1}$, \\ Steve Vassili Missambou Mandilou², Sabrina Nadia Bouithy5, \\ Evrard Romaric Nika², Jean Robert Mabiala Babela ${ }^{1,2}$
}

\footnotetext{
${ }^{1}$ Faculty of Health Sciences, Marien Ngouabi University of Brazzaville, Brazzaville, Republic of Congo

${ }^{2}$ Pediatric Services, Brazzaville University Hospital, Brazzaville, Republic of Congo

${ }^{3}$ Infectious Diseases Service, Brazzaville University Hospital, Brazzaville, Republic of Congo

${ }^{4}$ Department of Neonatology, Brazzaville University Hospital, Brazzaville, Republic of Congo

${ }^{5}$ Department of Internal Medicine and Cardiology, Talangai Hospital, Brazzaville, Republic of Congo

Email: *lucieatipo@hotmail.fr
}

How to cite this paper: Ikobo, L.C.O., Ibara, R.B.O., Ngakengni, N.Y., Babomi, L., Bowassa, G.E., Ngamo, L.T., Mandilou, S.V.M., Bouithy, S.N., Nika, E.R. and Babela, J.R.M. (2020) Proteinuria in Children Living with HIV on Highly Active Antiretroviral Therapy (Haart). Open Journal of Pediatrics, 10, 255-262.

https://doi.org/10.4236/ojped.2020.102026

Received: February 19, 2020

Accepted: May 5, 2020

Published: May 8, 2020

Copyright $\odot 2020$ by author(s) and Scientific Research Publishing Inc. This work is licensed under the Creative Commons Attribution International License (CC BY 4.0).

http://creativecommons.org/licenses/by/4.0/ (c) (i) Open Access

\begin{abstract}
Objective: To determine the prevalence of proteinuria in children living with HIV (CLHIV) and identify associated factors. Patients and methods: This was a cross-sectional, descriptive and analytical study carried out from April to August 2017 in the HIV care centres in Brazzaville and Pointe-Noire. The study included CLHIV with dipstick urinalysis test "Combur ${ }^{10}$ Test ${ }^{\circ}$ M". Results: Thirty seven CLHIV on HAART presented a proteinuria, $21.8 \%$. Children were male gender in 21 cases (56.8\%) and female gender in 16 cases (43.2\%). Mean age was $10.9 \pm 3.9$ years. The children were infected with type 1 virus in 35 cases (94.6\%), vertical transmission in all the cases (100\%). Children were living with HIV for about 2 to 4 years of average $n=18(48.6 \%)$ and they were WHO clinical stage 2 in 18 cases (48.6\%). 13 children (35\%) had CD4 level $<200$ cells $/ \mathrm{mm}^{3}$. All CLHIV (100\%) were on HAART thus $20(37.7 \%)$ on the combination of zidovudine (AZT), lamivudine (3TC) and nevirapine (NVP). This combination AZT, 3TC, NVP was a protective factor regarding the occurrence of proteinuria (OR: 0.43; IC (95\%). Conclusion: Proteinuria is less observed in CLHIV on HAART. Systematic screening and early management of proteinuria during follow-up of these children improve their survival.
\end{abstract}

\section{Keywords}

Children, HIV, HAART, Associated Factors, Proteinuria 


\section{Introduction}

Proteinuria is a renal complication frequently observed in children, including those infected with the acquired immunodeficiency virus (HIV/AIDS) [1]. Renal dysfunction is promoted by viral infection (HIV nephropathy), antiretroviral treatment (nephrotoxicity), but also by infectious complications and associated treatment [1] [2]. Immune activation by HIV leads to a state of chronic inflammation of the renal parenchyma, which may be one of the determinants of proteinuria and microalbuminuria [1] [3]. Diagnosis of renal impairment is based on renal biopsy; otherwise, proteinuria is used as a marker of renal dysfunction. Its occurrence during the course of viral infection is a poor prognostic factor in terms of survival [4] [5]. The prevalence of proteinuria in children living with HIV (PLHIV) has already been reported in the USA [6] and in some African countries [7] [8] [9]. The aim of this work was to determine the prevalence of proteinuria among HIV-positive children in Congo, to describe the epidemiological characteristics of CLHIV with proteinuria and to identify associated factors with the occurrence of proteinuria.

\section{Patients and Methods}

We carried out a descriptive cross-sectional study between April and August 2017, in the paediatric care centres of CLHIV in Brazzaville and Pointe Noire. As well as in the biomedical center IRIS for the quantitative assays of proteinuria. CLHIV aged 2 months to 17 years, with positive HIV serology, regularly followed up, with recent CD4 count (less than 12 months old) were included after informed consent of the parents. Children with renal malformations and those with disease that affects the kidneys were not included in the study. Sampling was simple and consecutive, CLHIV who met the selection criteria were systematically tested on admission with a reactive urine test strip. Thus, 170 children were selected for the study. Data were collected using a pre-determined survey form after consultation of follow-up registers.

The clinical investigation was a three-step process. At the first medical consultation; the interview provided information on the child's civil identity and personal history. The physical examination first permits us to assess the general anthropometric parameters (weight, height and body mass index). Then a complete physical examination to look for opportunistic infections. This was immediately coupled with the urine test strip examination, which consisted of measuring the proteinuria using a "Combur10 Test $\mathrm{M}$ strip" dipped in a sample of urine freshly collected by the investigator, followed by a reading of the dipstick. The reading method was visual and colorimetric and was performed by two investigators of the research team who had good visual acuity and no colour vision impairment. The test strip was positive when there was a shift from the initial pale pink colour to purple.

The paraclinical investigation at the second visit consisted primarily of the 24-hour quantitative assays of proteinuria. The test was performed using a " $\mathrm{Cli}$ - 
nitek status + SIEMENS" test strip meter on urine collected in a suitable five-litre container over 24 hours. The first morning micturition at approximately 7a.m. was done outside the container; the remaining micturition into the appropriate container until 24 hours later. The reading method was based on the same principle. The strip was positive when it turned from the initial yellow to green. These proteinuria results were then used for further analysis of the associated factors.

The study variables were epidemiological (age, sex, age of discovery of HIV infection, mode of transmission, type of virus, duration of disease course), clinical (the World Health Organization (WHO) clinical stages of the disease) and biological (CD4 cell count, proteinuria quantitative assay. Proteinuria was said to be "positive" when it was $\geq 1+$ on the urine test strip) and therapeutic variables (treatment protocol, duration of antiretroviral treatment as “ART”).

Data were entered and processed using SPSS version 20.0 and Microsoft Excel 2010. Qualitative variables were presented in numbers and percentages in parentheses. Quantitative variables were expressed as mean \pm standard deviation. The comparison of qualitative variables used Pearson's chi-square test, while the comparison of quantitative variables used Student's t-test. A univariate analysis was used to look for factors associated with proteinuria with calculation of odds ratio (OR) and their $95 \%$ confidence interval (CI). For comparisons the significance threshold was $<0.05$.

\section{Results}

One hundred and seventy CLHIV were included in the study, of whom 37 $(21.8 \%)$ had proteinuria. The sociodemographic, clinical and biological characteristics of all study subjects with an overall renal biological abnormality during this investigation are recorded in Table 1.

CLHIV with proteinuria were male in 21 cases (56.8\%) and female in 16 cases (43.2\%), for a sex ratio of 1.3. Their mean age was $10.9 \pm 3.9$ years (extremes of 2 and 17 years), with the most common age range being between 10 and 14 years $(\mathrm{n}=19 ; 51.3 \%)$. The children were infected with virus type $1(\mathrm{n}=35 ; 94.6 \%)$ and virus type $2(\mathrm{n}=2 ; 5.4 \%)$. Transmission was vertical among all HIV-positive individuals, and they had been living with HIV for an average of 2 to 4 years, $\mathrm{n}=$ 18 cases $(48.6 \%)$. The clinical and biological characteristics of CLHIV with proteinuria are shown in Table 2 . All children were on highly active antiretroviral therapy (HAART); Figure 1 shows the distribution of CLHIV with proteinuria according to the different types of protocols administered. Factors associated with proteinuria in CLHIV on HAART are listed in Table 3.

\section{Discussion}

This cross-sectional study is assessing the prevalence of proteinuria in a cohort of HIV-positive children from Congo under HAART and is also attempting to examine associated factors that may increase the risk of developing proteinuria in these children. The CLHIV management centres selected were those in the 
two major cities of the country. Congo is a country with a predominantly urban population [10]. The results of this study therefore provide an overview of the problem and can therefore be extrapolated to the national level. The analysis of proteinuria was done according to the standards of the American Society of Infectious Diseases (IDSA) [11]; this made it possible to exclude false proteinuria and thus avoid a bias in interpretation. On the other hand, the failure to perform a renal biopsy in case of proteinuria was a limitation for our study.

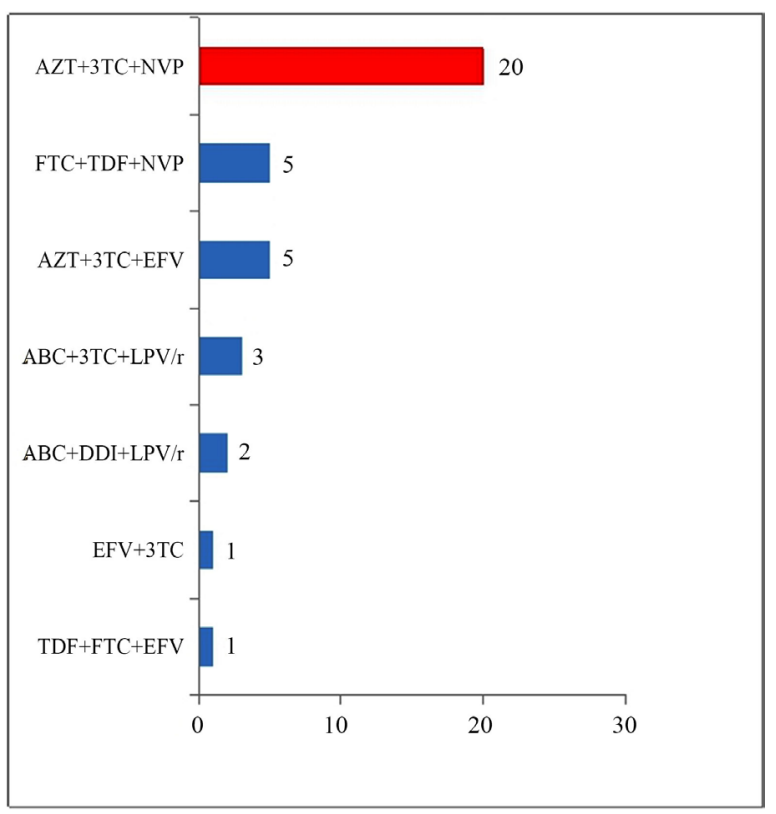

Figure 1. Distribution of proteinuria according to ART regimen.

Table 1. Characteristics of HIV-infected subjects on ART.

Gender: male $=27$ cases $(51 \%) ;$ female $=26$ cases $(49 \%) ;$ sex ratio $=1.03$

Age (year): mean age $10 \pm 3.4$; extremes (2 and 17)

Type Virus: HIV1 = $31(96 \%)$ cases

Transmission mode: vertical $=51(96 \%)$; other channels $=2(3.7 \%)$ cases

Duration of illness (years): mean duration: $4.7 \pm 2.9$; extremes ( 1 and 16)

Clinical stage according to WHO:

Stage 1: $14(26.4 \%)$ cases

Stage 2: $24(45.8 \%)$ cases

Stage 3: $11(20.8 \%)$ cases

Stage 4: $4(7.5 \%)$ cases

Immunological stage (CD4 count):

$<200$ cells $/ \mathrm{mm}^{3}: 20(37.8 \%)$ cases

$>499$ cells $/ \mathrm{mm}^{3}:=19(35.8 \%)$ cases

200 - 499 cells $/ \mathrm{mm}^{3}: 14(26.4 \%)$ cases

Duration of ART (years): Mean duration: $5.5 \pm 3.7$; extremes (1 and 16) 
Table 2. Clinical and biological characteristics of children with proteinuria.

\begin{tabular}{ccc}
\hline & $\mathrm{n}$ & $\%$ \\
\hline WHO Stage & 7 & 19 \\
Stage 1 & 18 & 48.6 \\
Stage 2 & 9 & 24.3 \\
Stage 3 & 3 & 8.1 \\
Stage 4 & & \\
CD4 Level & 14 & 38 \\
$<200$ cell/ml & 10 & 27 \\
$200-499$ cell//ml & 13 & 35 \\
$>499$ cell/ml & &
\end{tabular}

Table 3. Factors associated with the occurrence of proteinuria (variables are expressed as numbers and percentages in bracket).

\begin{tabular}{cccccc}
\hline \multicolumn{7}{c}{ Proteinuria } \\
& Yes $\mathrm{n}=37$ & No n $=133$ & OR & IC (95\%) & Value P \\
\hline Sex: male & $21(39.2)$ & $72(61.5)$ & 1.11 & $0.53-2.31$ & 0.77 \\
Duration of disease $\geq 2$ years & $32(86.4)$ & $111(94.8)$ & 1.26 & $0.44-3.61$ & 0.65 \\
Regimen AZT + 3TC + NVP & $20(54)$ & $97(82)$ & 0.43 & $0.206-0.92$ & 0.03 \\
WHO stage 2 $\geq 2$ years & $11(29.7)$ & $30(25.6)$ & 1.51 & $0.66-3.42$ & 0.32 \\
Cells $/ \mathrm{ml}<200$ & $14(37.8)$ & $30(25.6)$ & 2.09 & $0.95-4.55$ & 0.06 \\
\hline
\end{tabular}

The diagnosis of kidney damage is made by renal biopsy; otherwise, proteinuria and microalbuminuria were used. Proteinuria is a sensitive marker that allows confirmation of the diagnosis, referral to a glomerular or tubulo-interstitial cause, and assessment of therapeutic efficacy [5]. The current guidelines for urinalysis are based on the standards of the American Society of Infectious Diseases (IDSA), which recommends regular testing as the stigma of renal impairment, including proteinuria using a semi-quantitative urine test strip and a quantitative 24-hour proteinuria assay [11], due to the lack of specific evaluation criteria for children. This is the approach used in our study, as well as in other African studies [8] [9] [12] where the protocol recommended that a quantitative measurement be performed for all proteinuria greater than or equal to $1+$. The management of HIV infection in the Congo has benefited since 2010 from a national scale up with the implementation of the National AIDS Control Program (PNLS). Urine analysis is adapted to the recommendations of the PNLS [13] [14]. In fact, the program recommends that initial paraclinical explorations be carried out, including a urine test before starting ART, three months after the start of ART, and then every six months during follow-up, in the absence of alert signs related to renal dysfunction.

The prevalence of proteinuria in CLHIV on HAART in this study was $21.8 \%$. This prevalence is similar to those reported by Ekulu et al., 23.8\% in Kinshasa [8] and by Esezobor et al., 20.5\% in Nigeria [7]. However, Enobong et al., 31.6\% in Nigeria [15], Szczech et al., 32\% [16] and Chaparro et al., 33\% [6] in Miami in 
the USA, reported much higher results than ours. Much lower prevalences of $4 \%$ to $18.8 \%$ compared to ours were also reported in Africa [9] [15] [17]. The difference observed between the data in the literature and our result can certainly be explained by methodological differences in the size of our sample and the duration of the study.

We did not notice any statistical difference with regard to gender. A finding already made by Aghakhani et al. in 2008 [18], stating that there is no significant difference between sex and the occurrence of proteinuria in CLHIV. However, other authors have reported divergent results, with some authors reporting a predominantly male [5] [6] [12] and others a predominantly female [19]. The mean age of onset of proteinuria was $10.9 \pm 3.9$ years. In a study conducted in Ouagadougou on the prevalence of proteinuria in children followed for HIV infection, Coulibaly et al. reported a younger mean age of 8.8 years [12].

CLHIV were more frequently infected with the type 1 virus in a proportion of 94.6\%, close to that reported by Chaparro et al., $98.6 \%$ to [6]. Similarly, Coulibaly et al. [12], Barry et al. in Conakry [20] reported a similar result. These results can be explained by the fact that HIV1 is responsible for the pandemic. We believe that the predominant mother-to-child transmission observed in almost all the children in our series reflects the dysfunctions of the PNLS in Congo, and especially the weaknesses in the strategy for the prevention of mother-to-child transmission of HIV infection (PMTCT). This suggests that up stream screening of women of childbearing age should be stepped up, the PMTCT program should be revitalized, a mechanism should be put in place to trace the children being monitored, and children at risk should be screened early, with a view to the early detection and treatment of kidney dysfunction, thereby reducing the risk of kidney damage.

The majority of the children were classified as clinical stage II according to the WHO and had severe immunosuppression with CD $4<200$ cells $/ \mathrm{mm}^{3}$. This result is superimposable to those reported in the literature. Indeed, the authors state that proteinuria was likely to occur at low CD4 levels [6] [15] [20], and at advanced clinical stages of the disease [6] [15]. Thus, the occurrence of proteinuria appears to be correlated with the severity of viral infection.

The most commonly used regimen in our study combined zidovudine, lamivudine and nevirapine, comparable to that of Coulibaly et al. [12] and Esezobor et al. [7]. The responsibility of HIV infection and the HAART protocol for the occurrence of proteinuria in HIV-infected patients is difficult to establish in this study, despite the fact that ART are deleterious to the kidney, regardless of the duration of disease progression and the time of exposure to these molecules. The protocol combining zidovudine, lamivudine and nevirapine has been the most widely used first-line protocol in Congo since 2010, that is to say at the time of the study.

In this series, we did not find any factors associated with the occurrence of proteinuria. However, the univariate analysis shows that the protocol combining zidovudine, lamivudine and nevirapine seems, without drawing hasty conclu- 
sions, to be "protective" with regard to the occurrence of proteinuria; consequently, it reduces the risk of renal damage with a positive impact on their survival. The nephroprotective role induced by ART has also been reported by Penda et al. in Douala [9]. But taking into account the small sample size, we suggest that a large scale study should be conducted to better draw conclusions.

\section{Conclusion}

Proteinuria is relatively less observed in CLHIV on HAART. Systematic screening and early management of proteinuria during follow-up of this category of children improves their survival. There is no associated factor with the occurrence of proteinuria. However, the protocol combining zidovudine, lamivudine and nevirapine seems nephroprotective.

\section{Conflicts of Interest}

The authors declare no conflicts of interest regarding the publication of this paper.

\section{References}

[1] Tsiba, J.B., Mabiala Babela, J.R. and Senga, P. (2002) Proteinuria in School-Aged Children in the Congo. Archives de Pédiatrie, 12, 1401-1402.

https://doi.org/10.1016/j.arcped.2005.05.015

[2] Nochy, D., Glotz, D., Goucha, R., Pelletier, L. and Bariety, J. (1994) Kidney Damage during Human Immunodeficiency Infection (HIV). La Revue du Praticien, 44, 1494-1499.

[3] Daugas, E., Rougier, J.P. and Hill, G. (2005) HAART-Relate Néphropathies in HIV-Infected Patients. Kidney International, 67, 393-403.

https://doi.org/10.1111/j.1523-1755.2005.67096.x

[4] Izzedine, H. (2009) Kidney Disease during HIV Infection. The Infectiologists' Letter, 4, 146-156.

[5] Plaisier, E., Lescure, F.-X. and Ronco, P. (2012) Kidney and Human Immunodeficiency Virus Infection. La Presse Médicale, 41, 267-275. https://doi.org/10.1016/j.lpm.2011.11.011

[6] Chaparro, A.I., Mitchell, C.D., Abitbol, C.L., et al. (2008) Proteinuria in Children Infected with the Human Immunodeficiency Virus. The Journal of Pediatrics, 152, 844-849. https://doi.org/10.1016/j.jpeds.2007.11.007

[7] Esezobor, C., Iroha, E., Onifade, E., Akinsulie, A., Temiye, E. and Ezeaka, C. (2010) Prevalence of Proteinuria among HIV-Infected Children Attending a Tertiary Hospital in Lagos, Nigeria. Journal of Tropical Pediatrics, 56, 187-190. https://doi.org/10.1093/tropej/fmp090

[8] Ekulu, P.M., Nseka, N.M., Aloni, M.N., et al. (2012) Prevalence of Proteinuria and Its Association with HIV/AIDS in Congolese Children Living in Kinshasa, Democratic Republic of Congo. Néphrologie \& Thérapeutique, 8, 163-167. https://doi.org/10.1016/j.nephro.2011.09.004

[9] Penda, C.I., Eboumbou Moukoko, E.C., Koum, D.K., Moudze-kaptue, R., Fetchouang, F.V.R., Abomo, O.E., Eposse, C., et al. (2018) Prevalence of Proteinuria and Associated Factors in Children and Adolescents Infected with HIV on Antiretroviral Treatment at Laquintinie Hospital in Douala, Cameroon. The Journal of Medicine 
and Health Sciences, 19, 35-40.

[10] Ministry of Planning (2007) Spatial Planning and Integration. CNSEE, Brazzaville.

[11] Gupta, S.K., Eustace, J.A., Winston, J.A., et al. (2005) Guidelines for the Management of Chronic Kidney Disease in HIV-Infected Patients: Recommendations of the HIV Medicine Association of the Infectious Diseases Society of America. Clinical Infectious Diseases, 40, 1559-1585. https://doi.org/10.1086/430257

[12] Coulibaly, G., Kouéta, F., Ouédraogo, O., Dao, L., Lengani, A. and Yé, D. (2013) Prevalence of Proteinuria in Children Fool Owed-Up for HIV Infected at Pediatric University Hospital Charles-de-Gaulle (CHUP-CDG) of Ouagadougou. Bulletin de la Société de Pathologie Exotique, 106, 13-17. https://doi.org/10.1007/s13149-012-0270-9

[13] ONUSIDA (2014) Guidelines for the Prevention and Treatment of HIV Infection in the Congo.

[14] Mpemba Loufoua-Lemay, A.B. and Nzingoula, S. (2003) AIDS at the CHU of Brazzaville: Experience of the Pediatrics Department "Big Children". Bulletin de la Société de Pathologie Exotique, 96, 291-294.

[15] Enobong, I.E., Mkpouto, A.E., Udeme, E.E. and Itemobong, E.S. (2012) Determining the Prévalence of Human Immunodeficiency Virus Associated Nephropathy (HIVAN) Using Proteinuria and Ultrasound Findings in a Nigerian Paediatric HIV Population. The Pan African Medical Journal, 11, 13.

[16] Szczech, L.A., Gange, S.J., van der Horst, C., et al. (2002) Predictors of Proteinuria and Renal Failure among Women with HIV Infection. Kidney International, 61, 195-202. https://doi.org/10.1046/j.1523-1755.2002.00094.x

[17] Eke, F.U., Anochie, I.C., Okpere, A.N., et al. (2007) Proteinuria in HIV Positive Children a Pilot Study. Pediatric Nephrology, 22, 1456.

[18] Aghakhani, A., Eslamifar, A., Ramezani, A., et al. (2008) Frequency and Associated Factor of Proteinuria in Iranian HIV-Positive Patient. International Journal of Infectious Diseases, 12, 490-494. https://doi.org/10.1016/j.ijid.2008.01.009

[19] Dondo, V., Majuru, H.A., Nathoo, K.J., Chirehwa, M. and Mufandaedza, Z. (2013) Renal Abnormalities among HIV Infected, Antiretroviral Naive Children, Harare, Zimbabwe: A Cross-Sectional Study. BMC Pediatrics, 13, Article No. 75. https://doi.org/10.1186/1471-2431-13-75

[20] Barry Mamadou, C., Diallo Mohamed, L., Diallo Ibrahima, S., Doukouré Mamadou, A., Bangoura M'mah, A., Dia, H., et al. (2019) HIV Infection in Children 0 to 15 Years Old: Epidemiological, Clinical and Therapeutic Aspects at the CMC Matam Outpatient Treatment Center. Revue Internationale des Sciences Médicales d Abidjan, 21, 190-195. 